Journal of Nano Research Vol. 28 (2014) pp 51-61

Online available since 2014/Jun/06 at www.scientific.net

(C) (2014) Trans Tech Publications, Switzerland

doi:10.4028/www.scientific.net/JNanoR.28.51

\title{
Chemical Functionalization of Carbon Nanotubes and its Effects on Electrical Conductivity
}

\author{
José Encarnación Moreno Marcelino, Enrique Vigueras Santiago, \\ Gustavo López Téllez and Susana Hernández López \\ 'LIDMA, Facultad de Química de la Universidad Autónoma del Estado de México, \\ Paseo Colón esquina con Paseo Tollocan, s/n. Z.C. 50000, Toluca, Estado de México \\ E-mail: shernandezl@uaemex.mx
}

[Submitted: April 16, 2013; revised: September 16, 2013; accepted: February 14, 2014]

Keywords: Electrical conductivity, powder, MWNT, functionalization.

\begin{abstract}
This work presents the study of the electrical conductivity in MWNT as a function of three different chemical functionalization conditions. Unmodified and chemically modified MWNT were characterized by microRaman spectroscopy, XPS and SEM whereas the electrical conductivity was determined by dust compression technique. MWNT were modified using three different oxidation conditions: (1) a mix of concentrated acids, $\mathrm{H}_{2} \mathrm{SO}_{4} / \mathrm{HNO}_{3}(3: 1, \mathrm{v} / \mathrm{v})$ sonicated for $2 \mathrm{~h}$; (2) same mixture as (1) but using mechanical stirring for $6 \mathrm{~h}$ and (3) a reflux of an aqueous solution of $\mathrm{HNO}_{3}(20 \%, \mathrm{v} / \mathrm{v})$ and mechanical stirring for $6 \mathrm{~h}$. The characterization evidenced different functionalization degrees, based on the formation and detection of functional groups such as ether, carbonyl and carboxyl in different percentages. The unmodified CNT presented a conductivity of $510 \mathrm{~S} / \mathrm{m}$ which decreased as the functionalization degree increased. For reactions (1) and (2) such conductivity was reduced by 8.8 and $15.5 \%$, respectively, whereas for condition (3) it only decreased $0.98 \%$.
\end{abstract}

\section{Introduction}

The unique properties of carbon nanotubes, CNT such as excellent mechanical and electrical properties make them attractive for applications in many scientific and technological fields. They are quasi-one dimensional cylindrical tubules formed from wrapped tubular graphite sheets and possess extremely high aspect ratio, high elastic modulus, low density and great resistance to failure. The exact magnitude of these properties depends on the diameter and chirality of the CNT and whether they are in single-wall or multiwall form [1]. Due to their physico-chemical and geometric characteristics, CNT are insoluble in any solvent, they form tight long bundles due to van der Waals interactions and bundles can form a dense entangled network. This aggregation is not desirable for preparing polymer composites containing CNT and surface modification of the CNT is usually required in order to improve compatibility between the CNTs and the polymer matrix. Thus, separation of these bundles and dispersion and alignment of the individual CNT are crucial steps for several applications, hence becoming an important challenge in composite materials preparation. The covalent attachment of functional groups to the surface of CNT can improve the dispersion of CNT due to interactions with the polymer matrix, however it must be noted that these functional groups might introduce defects on the walls of the perfect structure of the CNT [2-4], and as a consequence, their bulk electrical properties could be modified $[5,6]$.

There are several surface functionalization techniques but oxidation is one of the most useful and widely studied methods. Some oxidant reactants include the use of concentrated mixtures of acids as $\mathrm{H}_{2} \mathrm{SO}_{4} / \mathrm{HNO}_{3}$, but also $\mathrm{HNO}_{3}, \mathrm{KMnO}_{4}, \mathrm{OsO}_{4}, \mathrm{O}_{3}$, among others [2, 6-11]. As a result, functional groups as carboxylic acid, ether, quinone, hydroxyl, and others will cover the ends and walls of the CNT which consequently will improve CNT dispersion in organic solvents or polymer matrix. Liu et al [2] was the first in reporting the use of a concentrated mixture of $\mathrm{H}_{2} \mathrm{SO}_{4} / \mathrm{HNO}_{3}$ (3:1) in order to cut and purify long ropes of SWNT, producing thus shortened pipes (open ended) with carboxylic acid groups at the open end. Zhang et al. [7], evaluated the oxidizing power and effect of three 